\title{
A systematic review and meta-analysis of radical cystectomy in the treatment of muscular invasive bladder cancer (MIBC)
}

\author{
Juan Zhao", Li Zhoü, Yan Pan\#, Lan Chen \\ Urology Surgery, Hospital of Chengdu University of Traditional Chinese Medicine, Chengdu, China \\ Contributions: (I) Conception and design: J Zhao, L Chen; (II) Administrative support: L Zhou; (III) Provision of study materials or patients: J Zhao, \\ L Zhou, Yan Pan; (IV) Collection and assembly of data: All authors; (V) Data analysis and interpretation: J Zhao, Y Pan, L Chen; (VI) Manuscript \\ writing: All authors; (VII) Final approval of manuscript: All authors. \\ "These authors contributed equally to this work. \\ Correspondence to: Lan Chen. No. 39 Shi-er-qiao Road, Chengdu 610072, China. Email: landychen0829@126.com.
}

\begin{abstract}
Background: A meta-analysis was conducted to evaluate the curative effect of radical cystectomy in the treatment of muscular invasive bladder cancer (MIBC).

Methods: Chinese and English databases were searched using free combinations of the terms "bladder cancer," "radical cystectomy," "muscle invasive bladder cancer," and "bladder preservation." Review Manager 5.3 software was used for the meta-analysis.

Results: A total of 12 articles were included in the meta-analysis, most of which had low-bias risk and were of medium and high quality. A funnel chart showed that the circles of some studies were basically symmetrical with the midline, suggesting that the research accuracy was high, the publications were not biased, and the final conclusions were credible. Twelve articles analyzed patients' 5-year survival rate in randomized controlled trials (RCTs). In these RCTs, the experimental group (expt group) comprised 775 cases and the control group (ctrl group) comprised 766 cases. A heterogeneity test using the fixed-effects model (FEM) showed $\mathrm{Chi}^{2}=2.19$, df $=11, \mathrm{I}^{2}=0 \%, \mathrm{P}=1.00>0.1, \mathrm{Z}=2.57$, odds ratio $(\mathrm{OR})=1.30,95 \%$ confidence interval (CI): $1.06-1.59$, and $\mathrm{P}=0.01<0.05 .3$ articles analyzed patients' 10 -year survival rates in RCTs. These trials comprised a total of 417 patients (209 in the expt group and 208 in the ctrl group). The overall heterogeneity test showed $\mathrm{Chi}^{2}=0.40, \mathrm{df}=2, \mathrm{I}^{2}=0 \%, \mathrm{P}=0.82>0.1, \mathrm{Z}=1.42$, OR $=1.32,95 \% \mathrm{CI}: 0.90-1.94$, and $\mathrm{P}=0.16>0.05$. 6 articles analyzed 5-year distant metastasis rates (DMRs) in RCTs. The overall heterogeneity test showed $\mathrm{Chi}^{2}=1.68, \mathrm{df}=5, \mathrm{I}^{2}=0 \%, \mathrm{P}=0.89>0.1, \mathrm{Z}=1.70, \mathrm{OR}=1.28,95 \% \mathrm{CI}: 0.96-1.71$, and $\left.\mathrm{P}=0.09>0.05\right)$.
\end{abstract}

Discussion: Our meta-analysis confirmed that radical cystectomy is effective in the treatment of MIBC and is worthy of clinical promotion.

Keywords: Radical cystectomy; muscular invasive bladder cancer (MIBC); bladder preservation; survival rate; distant metastasis rate (DMR)

Submitted Jun 09, 2021. Accepted for publication Jul 27, 2021.

doi: 10.21037/tau-21-564

View this article at: https://dx.doi.org/10.21037/tau-21-564

\section{Introduction}

Bladder cancer (BC) refers to the cancerous transformation of a layer of mucosal cells covering the surface of the bladder. BC is a malignant disease with high morbidity and high mortality worldwide. In China, BC accounts for the highest number of new patients and deaths among all urinary tract tumors (1). According to research reports, the incidence of BC in China in 2015 was 580/1,000, ranking it 13 th among systemic malignant tumors; the incidence among males was $883 / 1,000$, ranking it 7 th; and the incidence among females was $261 / 1,000$, ranking it 17 th (2). In 2015, the mortality rate of BC in China was 2.37 per 100,000 , ranking it 13 th among systemic malignant tumors; the mortality rate in males was 3.56 per 100,000 , and the 
mortality rate in females was 1.11 per 100,000 (3). As the data shows, the morbidity and mortality rates of males are much higher (about 3 times) than those of females. Clinically, BC can be classified into muscular invasive bladder cancer (MIBC) and non-MIBC according to the depth of tumor invasion (4). An invading detrusor tumor is referred to as MIBC (5). MIBC is prone to lymph node and other organ metastasis, and the 5 -year overall survival rate is about $40-60 \%(6)$.

Radical cystectomy is the standard method of treatment of MIBC in most western countries. Like urinary diversion, physical status and life expectancy are the basic factors affecting the selection of radical cystectomy (7). Radical cystectomy is reserved for patients who have longer survival expectations, who do not have other underlying diseases, and who have a good physical status (8). Scholars have described different methods for improving urinary control and retention of sexual function; however, there is no consensus on which method best retains function. The effect of "function retention" on tumor control remains a concern (9).

To provide good guidelines for the clinical treatment of MIBC, a meta-analysis was conducted to systematically evaluate the curative effect and bladder preservation of radical cystectomy for MIBC patients as reported in articles published since the establishment of the selected databases. We present the following article in accordance with the PRISMA reporting checklist (available at https://dx.doi. org/10.21037/tau-21-564).

\section{Methods}

\section{Articles retrieval}

The PubMed, CMCI, Medline, Embase, Chinese Biomedical Literature, China National Knowledge Network (CNKI), Wanfang, VIP, and Google Scholar databases were searched to retrieve articles on randomized controlled trials (RCTs) examining the use of radical cystectomy in the treatment of MIBC patients published from the establishment of the databases to December 25, 2020. The Boolean logic retrieval method was adopted to select the relevant articles by using compound logic retrieval. The Chinese databases were searched using free combinations of the terms "bladder cancer," "radical cystectomy," "muscle invasive bladder cancer," and "bladder preservation." The English databases were searched using free combinations of the same terms. The quality of the articles was evaluated according to the RevMan 5.3 software provided by the Cochrane system. After the articles were retrieved for several times, the updated research progress had to be known by consulting the experts and researchers.

\section{Inclusion and exclusion criteria of articles}

To be eligible for inclusion in the meta-analysis, the articles had to meet the following inclusion criteria: (I) include a RCT; (II) include the subjects who had been clinically diagnosed with MIBC according to the diagnostic criteria specified by the world health organization (WHO); (II) include a pathological control analysis and index comparisons within $95 \%$ CIs; (IV) include an experimental (expt) group of MIBC patients who had been treated with radical cystectomy.

Articles were excluded from the meta-analysis if they met any of the following exclusion criteria: (I) involved overlapping research subjects; (II) comprised content of repeatedly published research; (III) comprised content about a related literature review or case report; (IV) contained unavailable or in complete data; and/or (V) the study was not related to radical cystectomy.

Tao senior experts independently screened the title, abstract, and the full text of each article. If the experts held inconsistent views, consensus was reached via a discussion between the 2 experts or an arbitration by a third expert.

\section{Evaluation indicators of different treatment methods}

To be included in the meta-analysis, the articles had to examine any of the following indicators: the 5-year survival rate, the 10-year survival rate, or the 5-year distant metastasis rate (DMR) after surgery. The odds ratios (ORs) of the 5 -year survival rate, the 10 -year survival rate, and the 5 -year DMR of patients of the 2 groups were compared and analyzed.

\section{Data extraction}

Using a unified Excel spreadsheet, 2 experts extracted the data independently. If the 2 experts held inconsistent views, consensus was reached via a discussion between the 2 experts or an arbitration by a third expert. The data extracted included the: title, first author, publication year, name of the publication; published year; general information of the research subjects (including average age, gender, and number), and follow-up period. The extracted evaluation indicators were the 5 -year survival rate, the 10 -year 
Table 1 Specific meanings of the 4 levels in GRADE

\begin{tabular}{llll}
\hline Level & Definition & Score(s) \\
\hline Very low & The estimated effect value was not credible, as it differed greatly from the real value & $\leq 1$ \\
Low & The credibility of the estimated effect value was poor, as it differed greatly from the real value & $\leq 1$ \\
Medium & The credibility of the estimated effect value was sound, as it was close to the real value & $2-5$ \\
High & The credibility of the estimated effect value was high, as it was consistent with the real value & $\geq 6$ \\
\hline
\end{tabular}

survival rate, and the 5-year DMR after the surgery.

\section{Assessment of bias risk}

The bias risk of the articles was assessed by 2 researchers. If there was any dispute between them, the results were determined via a discussion between the 2 experts or an arbitration by a third expert. In this study, the Cochrane Collaboration was used as a tool to assess the bias risk of the RCTs. The evaluation criteria included random allocation plan generation, blind selection, allocation plan hiding, the completeness of data results, and the research results. Classifications of "high-bias risk," "low-bias risk," and "unclear-bias risk" were determined based on the above 5 criteria.

\section{Quality evaluation}

The bias risk was assessed by the 2 researchers. If there was any dispute between them, the results were determined via a discussion between the 2 experts or an arbitration by a third expert. In this study, the GRADE standard in the Cochrane Collaboration was used for quality classification. An article with a score of 6 and above was considered high quality (with a low-bias risk); an article with a score of 1 and below was considered low quality (with a high-bias risk); and an article with a score of 2-5 was considered medium quality (with an unclear-bias risk). Table 1 sets out the specific meanings of the 4 grades of the GRADE quality classification system.

\section{Statistical analysis}

StataSE12.0 software was adopted for the statistical analysis. ORs and $95 \%$ confidence intervals (CIs) were used to evaluate and compare the 5-year survival rate, the 10-year survival rate, and the 5 -year DMR of patients treated with radical cystectomy and bladder preservation. To evaluate the bias risk of the included articles, the assessment results of the bias risk analyses were drawn using Review Manager
5.3 software. The effect was expressed by a $95 \%$ CI. When $\mathrm{P}>0.01$ and $\mathrm{I}^{2}<50 \%$, a fixed-effects model (FEM) was used for the meta-analysis. When $\mathrm{P}<0.01$ and $\mathrm{I}^{2}>50 \%$, a randomeffects model (REM) was used for the meta-analysis.

\section{Results}

\section{Article retrieval results and basic information of the included articles}

Two hundred and thirty-five articles were retrieved, 51 articles were excluded after checking their titles and abstract, leaving 184 articles remaining. One hundred and thirty-six articles were excluded from repeated publication and the first author could not be obtained, and 48 articles remained. After reading the full text, 36 articles were excluded and 12 articles were eventually included for metaanalysis. The specific process of article retrieval was shown in Figure 1. The main reasons for exclusion were as follows: duplicated research subjects; not the case-based randomized control analysis, no bladder cancer surgery for subjects, and available research information and data. Figure 2 shows the classification results based on the GRADE quality. Nine articles had scores $\geq 6,7$ articles had scores of $3-5$, and 2 articles had scores $\leq 1$.

Twelve articles, comprising 1,541 patients, met the inclusion criteria. All 12 articles were small-sample studies with sample sizes ranging from 35-92. All research subjects were aged over 18 years old. The average age, gender, number, and follow-up duration of the patients in the expt group and the ctrl group were described and analyzed in all 12 articles. Tables 2 and 3 set out the basic information of the research subjects. The 5-year survival rates of the patients are set out in Table 3.

\section{Evaluation of bias risk of the included articles}

The assessment results of the bias risk of the included articles are shown in Figures 3 and 4, which were drawn 


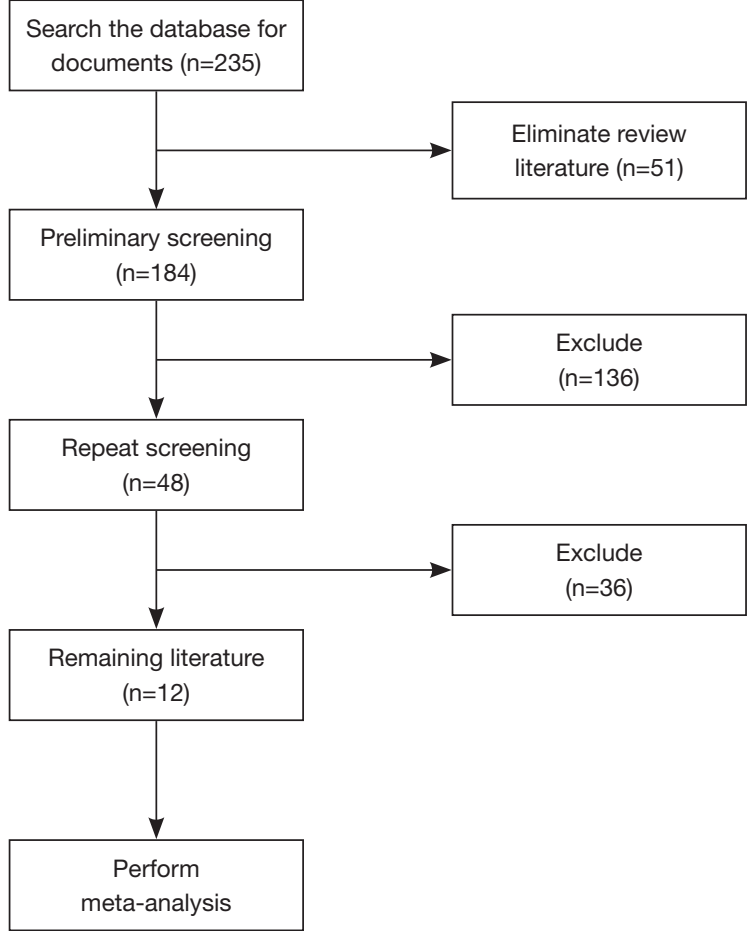

Figure 1 Articles retrieval process.

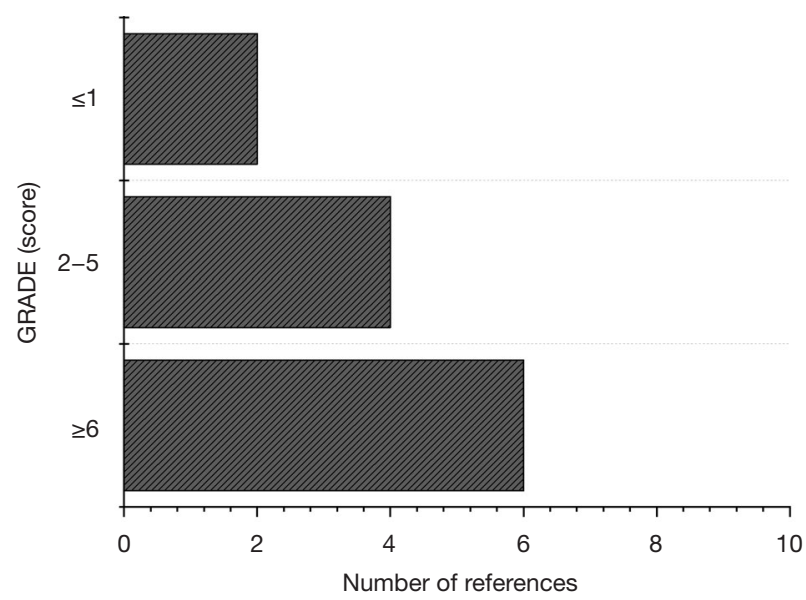

Figure 2 The classification results based on the GRADE quality.

using Review Manager 5.3 software. Among the 12 RCTs in this study, 3 articles (10-12) described the correct random allocation method, but only 2 articles $(13,14)$ described both the correct random allocation method and the detailed allocation hiding. In addition, 1 article (15) adopted the blinding method. However, the measurement indicators in present study were laboratory indicators determined by computer; thus, all articles could be considered to have adopted the blinding method correctly.

\section{Analysis on publication bias}

A funnel chart (see Figure 5) was drawn using RevMan5.3. The circles of some studies were basically symmetrical with the midline, which indicated that the research accuracy was high, the publication was not biased, and the final conclusions reached were credible.

\section{Meta-analysis results of the 5-year survival rate}

Twelve articles analyzed the 5-year survival rate in RCTs. The total number of cases comprised 1.292 patients, including 775 patients in the expt group and 766 patients in the ctrl group. The overall heterogeneity was tested $\left(\mathrm{Chi}^{2}\right.$ $=2.19, \mathrm{df}=11, \mathrm{I}^{2}=0 \%$, and $\left.\mathrm{P}=1.00>0.1\right)$. The research results of Smith (2013) accounted for the highest percentage of the final combined results (12.9\%), followed by those of Mmeje (2013) (12.1\%). In addition, the horizontal line of the $95 \%$ $\mathrm{CI}$ of all the studies crossed the invalid vertical line. The FEM analysis results indicated that the difference between the expt group and ctrl group was not statistically significant $(\mathrm{Z}=2.57, \mathrm{OR}=1.30,95 \% \mathrm{CI}: 1.06-1.59$, and $\mathrm{P}=0.01<0.05$; see Figure 6).

In this study, all of the 12 included articles were metaanalyzed using the REM, and changes in the combined effect value were calculated (see Figure 7). In relation to the combined 5-year survival rate, the results under the REM were as follows: $\mathrm{OR}=1.30,95 \% \mathrm{CI}: 1.06-1.59$, and $\mathrm{P}=0.01$. A comparison of the combined effect values of the FEM and REM showed that the calculated results were almost the same under the different models, indicating that the 12 included articles showed good sensitivity. In addition, the robustness and clinical similarity of the studies were high; thus, the final conclusion was reliable.

\section{Meta-analysis results of 10-year survival rate}

A total of 3 articles analyzed the 10-year survival rate in RCTs. There were 417 cases in total, comprising 209 cases in expt group and 208 cases in Ctrl group. The overall heterogeneity test showed $\mathrm{Chi}^{2}=0.40, \mathrm{df}=2, \mathrm{I}^{2}=0 \%$, and $\mathrm{P}=0.82>0.1$. The research results of Dunst (2001) accounted for the highest percentage $(41.3 \%)$ of the final combined results, followed by the research results of McConkey DJ 
Table 2 Basic information of the included articles

\begin{tabular}{|c|c|c|c|c|c|c|c|}
\hline The first author & $\begin{array}{c}\text { Published } \\
\text { year }\end{array}$ & $\begin{array}{l}\text { Sample size } \\
\text { (cases) }\end{array}$ & $\begin{array}{c}\text { Males/ } \\
\text { females }\end{array}$ & $\begin{array}{l}\text { Research } \\
\text { method }\end{array}$ & Age (years) & $\begin{array}{l}\text { Neoplasm } \\
\text { staging }\end{array}$ & $\begin{array}{c}\text { Follow-up } \\
\text { period (months) }\end{array}$ \\
\hline Williamson SR & 2010 (1) & 70 & $45 / 25$ & Retrospective analysis & $42.4 \pm 9.7$ & $\mathrm{~T}_{2-4} \mathrm{~N}_{\chi} \mathrm{M}_{0}$ & $1-152$ \\
\hline Collins JW & $2014(2)$ & 76 & $42 / 34$ & Retrospective analysis & $62.6 \pm 9.9$ & $\mathrm{~T}_{2-4} \mathrm{NoM}_{0}$ & $2-64$ \\
\hline Aboumarzouk OM & $2012(3)$ & 98 & $56 / 42$ & Retrospective analysis & $44.8 \pm 8.5$ & 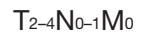 & $3-85$ \\
\hline McConkey DJ & $2015(6)$ & 148 & $85 / 64$ & Retrospective analysis & $28.7 \pm 6.5$ & $\mathrm{~T}_{2-4} \mathrm{~N}_{\chi} \mathrm{M}_{0}$ & $4-69$ \\
\hline Smith ZL & $2013(7)$ & 178 & $96 / 82$ & Retrospective analysis & $66.1 \pm 7.3$ & $\mathrm{~T}_{2-4} \mathrm{~N} 0 \mathrm{M}_{0}$ & $3-164$ \\
\hline Dunst J & 2001 (8) & 171 & $103 / 68$ & Retrospective analysis & / & $\mathrm{T}_{2-4} \mathrm{~N}_{0} \mathrm{M}_{0}$ & $4-69$ \\
\hline Tränkenschuh W & 2019 (12) & 90 & $52 / 38$ & Retrospective analysis & $42.4 \pm 9.7$ & $\mathrm{~T}_{2-4} \mathrm{~N}_{0-1} \mathrm{M}_{0}$ & $3-162$ \\
\hline
\end{tabular}

Table 3 Comparison of survival rates in the included articles

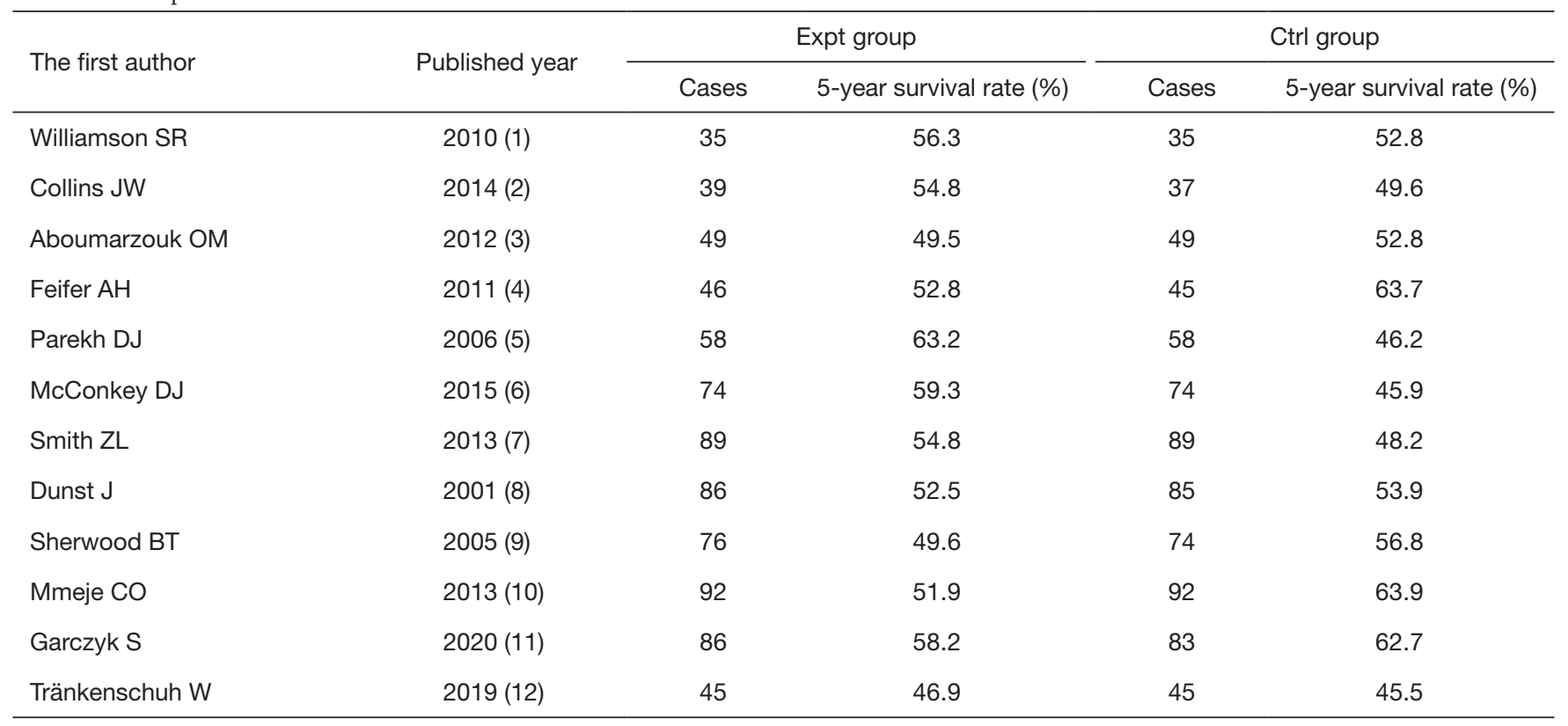

(2015) (37.7\%). The horizontal line and the invalid vertical line of the $95 \% \mathrm{CI}$ of the 3 articles crossed; thus, the FEM was adopted for the analysis. The results revealed that the difference between the expt group and the Ctrl group was not statistically significant (see Figure $8 ; Z=1.42, \mathrm{OR}=1.32$, 95\% CI: $0.90-1.94$, and $\mathrm{P}=0.16>0.05)$.

\section{Meta-analysis results of the 5-year DMR}

A total of 6 articles analyzed the 5 -year DMR in RCTs. The total number of cases was 763 , comprising 383 patients in the expt group and 380 patients in the ctrl group. The overall heterogeneity test showed $\mathrm{Chi}^{2}=1.68, \mathrm{df}=5, \mathrm{I}^{2}=0 \%$, 


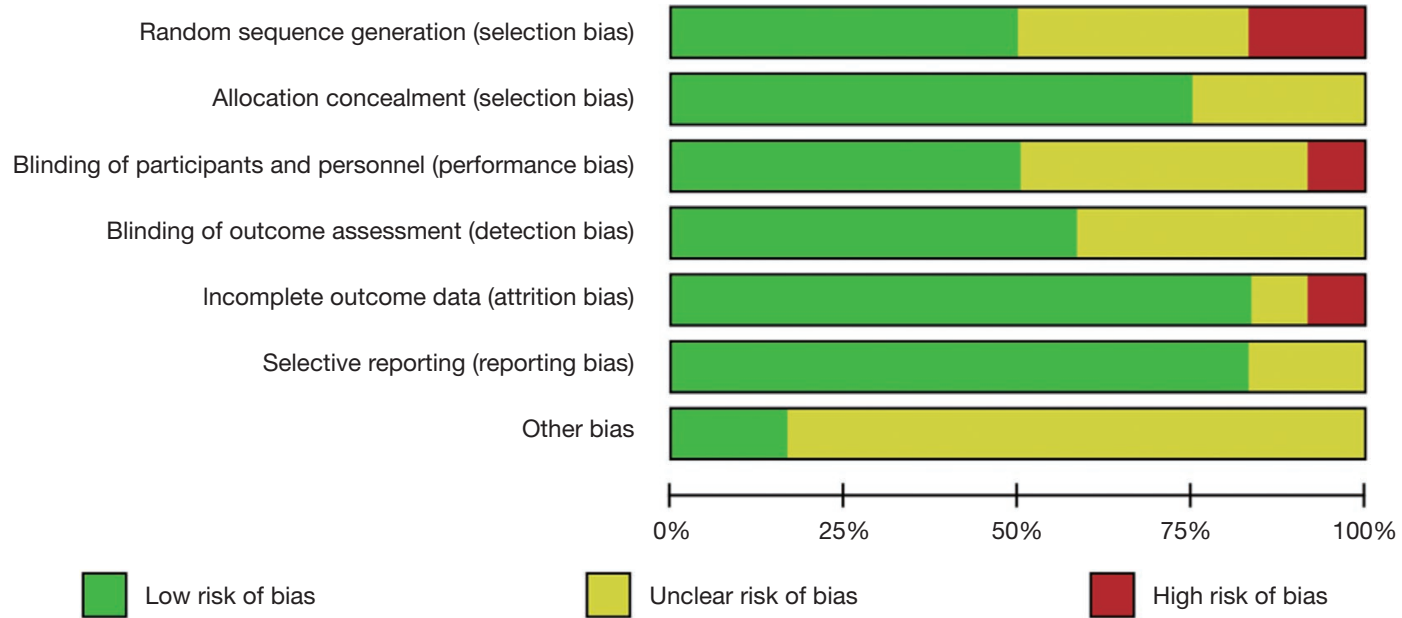

Figure 3 Bar chart for assessment of bias risk of the included articles.

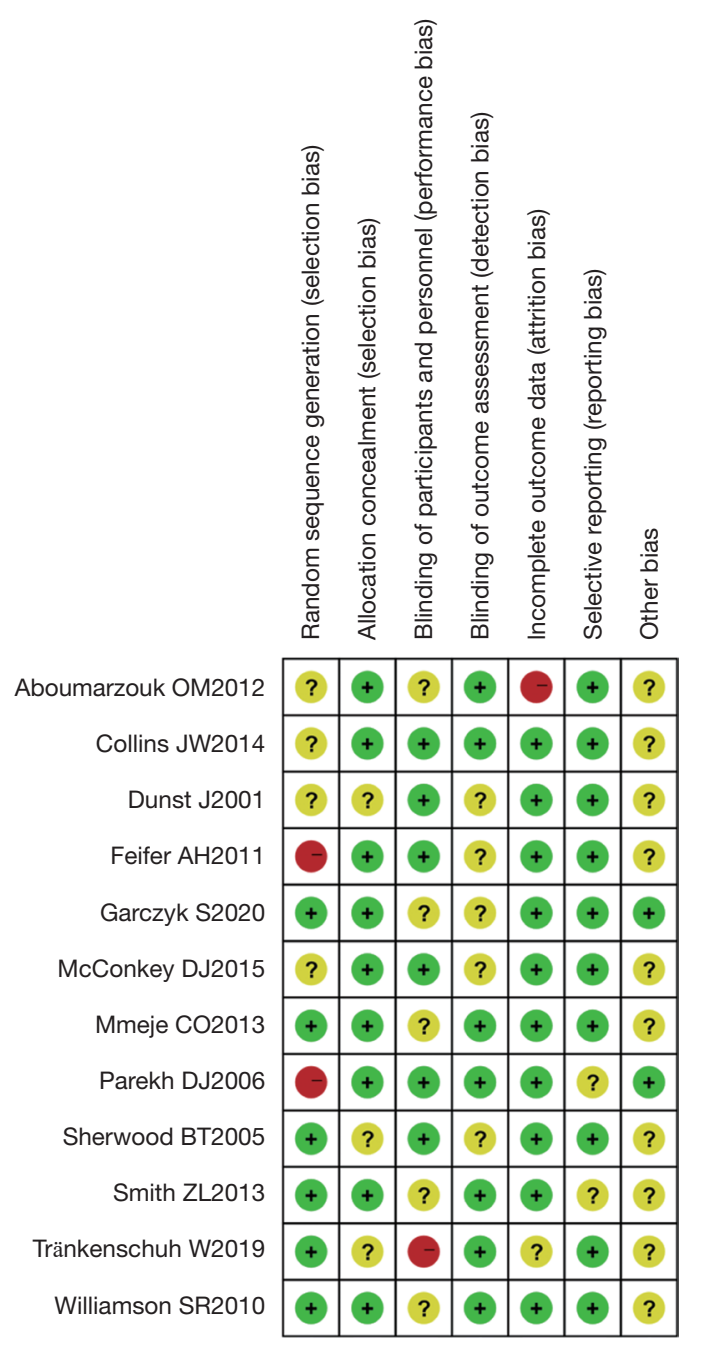

Figure 4 Assessment results of the bias risk of the included articles.

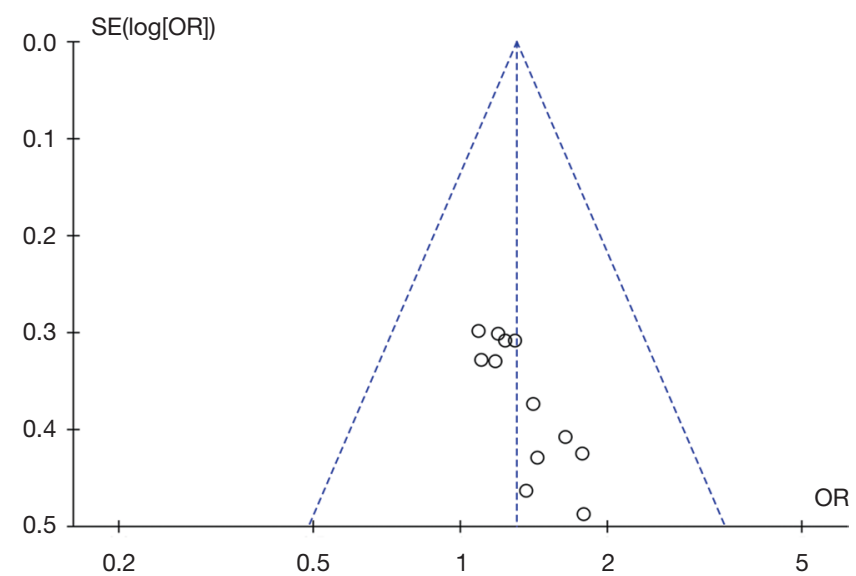

Figure 5 Funnel chart of the included articles.

and $\mathrm{P}=0.89>0.1$ (see Figure 9). The research results of Mmeje (2013) accounted for the highest percentage (26.0\%) of the final combined results, followed by the research results of Smith (2013) (37.7\%). The horizontal line crossed the invalid vertical line of the $95 \%$ CI of the 6 articles; thus the FEM was adopted. The results showed that the difference between expt group and the ctrl group was not statistically significant $(\mathrm{Z}=1.70$, OR $=1.28,95 \%$ CI: 0.96 1.71 , and $\mathrm{P}=0.09>0.05)$.

\section{Discussion}

In this study, a meta-analysis was conducted to evaluate the curative effects of radical cystectomy and bladder 


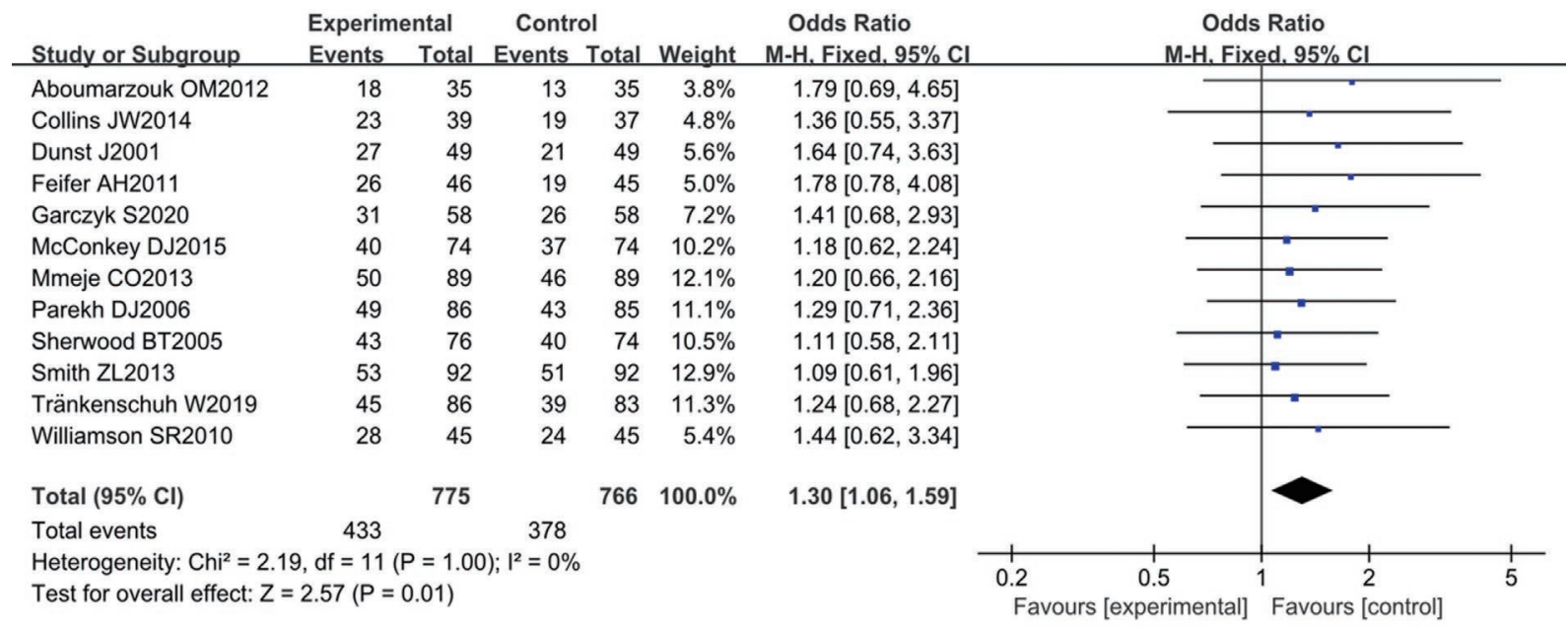

Figure 6 Forest map for 5-year survival rate under FEM. FEM, fixed-effects model.

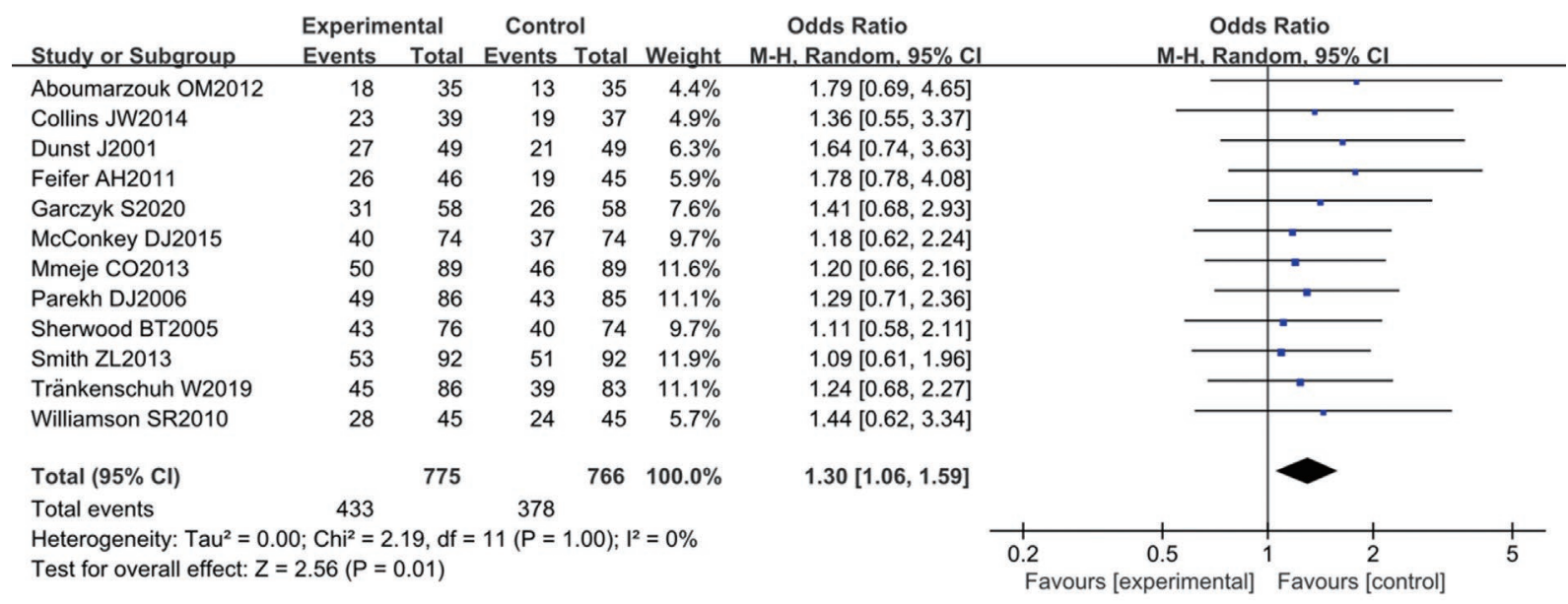

Figure 7 Forest map for the 5-year survival rate under the random effect model.

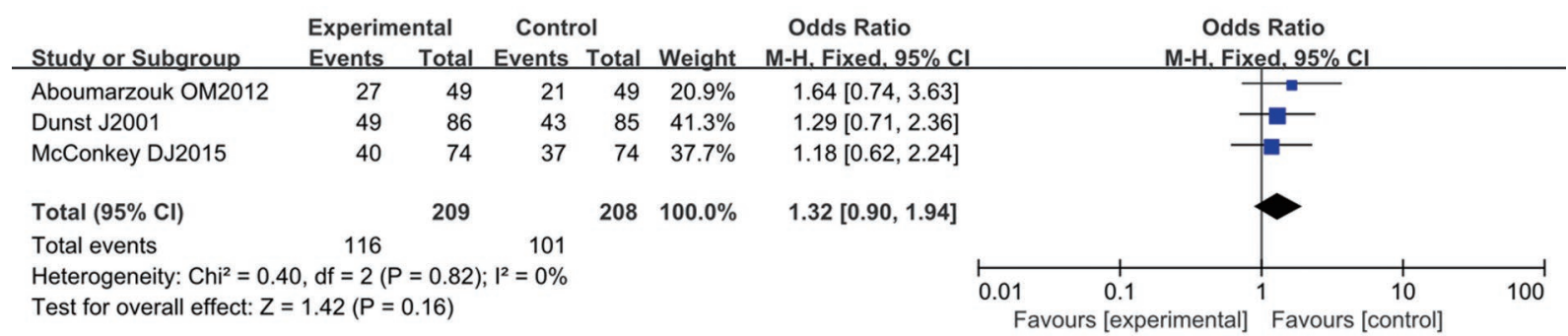

Figure 8 Forest map for 10-year survival rate. 


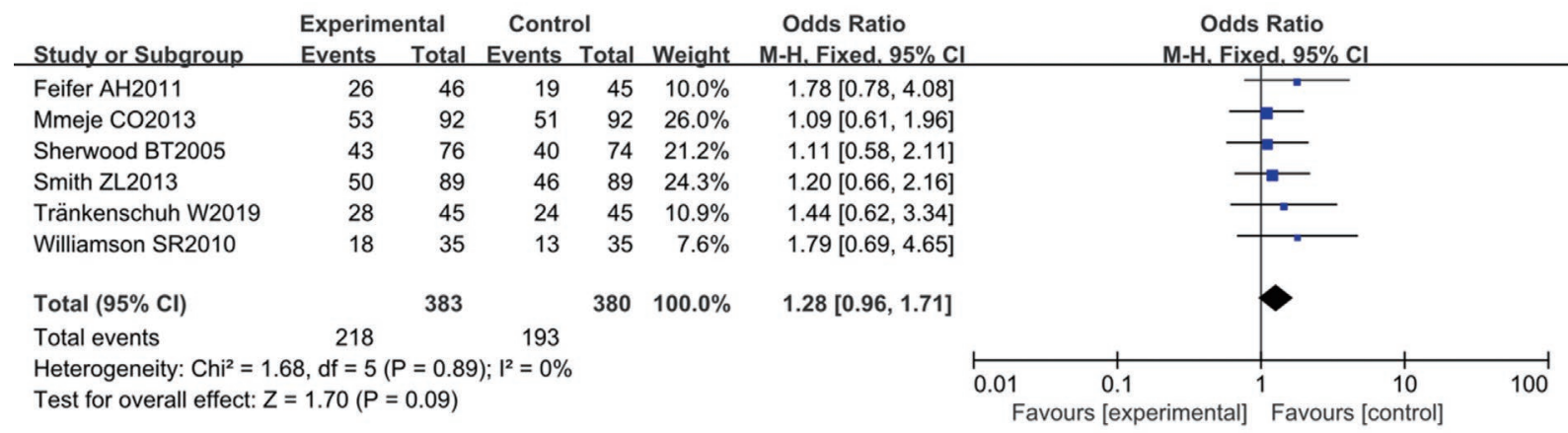

Figure 9 Forest map of the 5-year DMR. DMR, distant metastasis rate.

preservation in the treatment of MIBC. The results showed that the included studies had high accuracy and there was no bias in the publications, and the final conclusions were credible.

12 articles analyzed the 5 -year survival rate in RCTs, and tested overall heterogeneity $\left(\mathrm{Chi}^{2}=2.19, \mathrm{df}=11, \mathrm{I}^{2}=0 \%\right.$, and $\mathrm{P}=1.00>0.1)$. The analysis results of the FEM revealed that the 2 groups did not differ significantly. These results are consistent with those of Veskimäe et al. (2020) (16). A comparison of the combined effect values of the FEM and the REM indicated that the calculated results were almost the same under the different effects models, suggesting that the 12 included articles showed good sensitivity. In addition, the robustness and clinical similarity of the studies were high; thus, the final conclusions were reliable.

Three articles analyzed the 10 -year survival rate in RCTs and tested the overall heterogeneity $\left(\mathrm{Chi}^{2}=0.40\right.$, $\mathrm{df}=2, \mathrm{I}^{2}=0 \%$, and $\mathrm{P}=0.82$ ). The horizontal line crossed with the invalid vertical line of the $95 \%$ CI. The analysis results of the FEM showed that the difference between 2 groups was not statistically significant (17). These findings are consistent with those of Campbell et al. (2018) (18). Six articles analyzed the 5-year DMR in RCTs and tested the overall heterogeneity $\left(\mathrm{Chi}^{2}=1.68, \mathrm{df}=5, \mathrm{I}^{2}=0 \%\right.$, and $\mathrm{P}=0.89>0.1)$. The analysis results of the FEM indicated that the 2 groups showed no statistically observable difference, which was consistent with the findings of Almassi et al. (2020) (19).

The clinical curative effect and safety of radical cystectomy and bladder preservation in the treatment of MIBC were systematically evaluated based on the metaanalysis. The 5-year survival rate after radical cystectomy was $46.9-63.2 \%$, and the 5 -year survival rate after bladder preservation was $45.5-63.7 \%$ (20). The analysis results of each group showed that there was no obvious difference in the 5-year survival rate, 10-year survival rate, and 5-year DMR after surgery. However, it should be noted that patients in the 2 groups were at different clinical cancer stages, had different surgical options, received different radiation doses, and underwent different comprehensive chemotherapy regimens, all of which may have affected the prognosis of patients. Multi-center, large-sample RCTs need to be conducted in the future to better evaluate the curative effects of the 2 treatment methods.

Among the 12 articles included in this study, 3 articles described the correct random allocation method, 2 articles described both the correct randomized allocation method and the detailed allocation hiding, and all articles used the blinding method correctly. Under the GRADE quality classification system, 9 articles had scores $\geq 6,7$ articles had scores of $2-5$, and 2 articles had scores $\leq 1$. The sample sizes of the research studies included in this meta-analysis were small, and the quality level of the included experiments was relatively good.

\section{Conclusions}

In this study, the Boolean logic retrieval method was adopted to select relevant articles by using compound logic retrieval to search the articles that used radical cystectomy (the expt group) or bladder preservation (the ctrl group) to treat MIBC. Twelve articles were selected for the metaanalysis to explore the curative effect of radical cystectomy for MIBC. The meta-analysis of this study confirmed that radical cystectomy had a good curative effect in the treatment of MIBC and was worthy of clinical promotion. The limitations of this study were that the quality of the research subjects was low, the heterogeneity was high, and 
the total sample size of the included articles was small. Thus, the sample sizes of clinical RCTs have to be expanded in the future for further verification. In conclusion, the results of this study provide a scientific theoretical basis for the treatment of MIBC by radical cystectomy.

\section{Acknowledgments}

Funding: Chengdu University of Traditional Chinese Medicine Fund (ZRQN2020012).

\section{Footnote}

Reporting Checklist: The authors have completed the PRISMA reporting checklist. Available at https://dx.doi. org/10.21037/tau-21-564

Conflicts of Interest: All authors have completed the ICMJE uniform disclosure form (available at https://dx.doi. org/10.21037/tau-21-564). The authors have no conflicts of interest to declare.

Ethical Statement: The authors are accountable for all aspects of the work in ensuring that questions related to the accuracy or integrity of any part of the work are appropriately investigated and resolved.

Open Access Statement: This is an Open Access article distributed in accordance with the Creative Commons Attribution-NonCommercial-NoDerivs 4.0 International License (CC BY-NC-ND 4.0), which permits the noncommercial replication and distribution of the article with the strict proviso that no changes or edits are made and the original work is properly cited (including links to both the formal publication through the relevant DOI and the license). See: https://creativecommons.org/licenses/by-nc-nd/4.0/.

\section{References}

1. Williamson SR, Montironi R, Lopez-Beltran A, et al. Diagnosis, evaluation and treatment of carcinoma in situ of the urinary bladder: the state of the art. Crit Rev Oncol Hematol 2010;76:112-26.

2. Shi H, Wang K, Yuan J, et al. A high monocyte-tolymphocyte ratio predicts poor prognosis in patients with radical cystectomy for bladder cancer. Transl Cancer Res 2020;9:5255-67.

3. Cumberbatch MG, Noon AP; on behalf of the EAU
Young Academic Urologists-Urothelial Cancer Working party. Epidemiology, aetiology and screening of bladder cancer. Transl Androl Urol 2019;8:5-11.

4. Feifer AH, Taylor JM, Tarin TV, et al. Maximizing cure for muscle-invasive bladder cancer: integration of surgery and chemotherapy. Eur Urol 2011;59:978-84.

5. Parekh DJ, Bochner BH, Dalbagni G. Superficial and muscle-invasive bladder cancer: principles of management for outcomes assessments. J Clin Oncol 2006;24:5519-27.

6. McConkey DJ, Choi W, Ochoa A, et al. Therapeutic opportunities in the intrinsic subtypes of muscleinvasive bladder cancer. Hematol Oncol Clin North Am 2015;29:377-94, x-xi.

7. Smith ZL, Christodouleas JP, Keefe SM, et al. Bladder preservation in the treatment of muscle-invasive bladder cancer (MIBC): a review of the literature and a practical approach to therapy. BJU Int 2013;112:13-25.

8. Dunst J, Rödel C, Zietman A, et al. Bladder preservation in muscle-invasive bladder cancer by conservative surgery and radiochemotherapy. Semin Surg Oncol 2001;20:24-32.

9. Sherwood BT, Jones GD, Mellon JK, et al. Concomitant chemoradiotherapy for muscle-invasive bladder cancer: the way forward for bladder preservation? Clin Oncol (R Coll Radiol) 2005;17:160-6.

10. Mmeje CO, Martin AD, Nunez-Nateras R, et al. Cost analysis of open radical cystectomy versus robot-assisted radical cystectomy. Curr Urol Rep 2013;14:26-31.

11. Garczyk S, Ortiz-Brüchle N, Schneider U, et al. NextGeneration Sequencing Reveals Potential Predictive Biomarkers and Targets of Therapy for Urothelial Carcinoma in Situ of the Urinary Bladder. Am J Pathol 2020;190:323-32.

12. Tränkenschuh W, Biesdorf AS, Papadimas N, et al. Mixed Adenocarcinomatous and Neuroendocrine Tumor of the Urinary Bladder With Concomitant Carcinoma In Situ: A Case Report With a Comprehensive Immunohistochemical Analysis and Review of the Literature. Int J Surg Pathol 2019;27:684-92.

13. Parekh DJ, Reis IM, Castle EP, et al. Robot-assisted radical cystectomy versus open radical cystectomy in patients with bladder cancer (RAZOR): an open-label, randomised, phase 3, non-inferiority trial. Lancet 2018;391:2525-36.

14. Satkunasivam R, Tallman CT, Taylor JM, et al. Robotassisted Radical Cystectomy Versus Open Radical Cystectomy: A Meta-analysis of Oncologic, Perioperative, and Complication-related outcomes. Eur Urol Oncol 2019;2:443-7.

15. Khetrapal P, Conroy S, Kelly JD, et al. Comparing open- 
radical cystectomy and robot-assisted radical cystectomy: current status and analysis of the evidence. Curr Opin Urol 2020;30:400-6.

16. Veskimäe E, Espinos EL, Bruins HM, et al. What Is the Prognostic and Clinical Importance of Urothelial and Nonurothelial Histological Variants of Bladder Cancer in Predicting Oncological Outcomes in Patients with Muscleinvasive and Metastatic Bladder Cancer? A European Association of Urology Muscle Invasive and Metastatic Bladder Cancer Guidelines Panel Systematic Review. Eur Urol Oncol 2019;2:625-42.

17. Zhong J, Switchenko J, Jegadeesh NK, et al. Comparison of Outcomes in Patients With Muscle-invasive Bladder Cancer Treated With Radical Cystectomy Versus Bladder Preservation. Am J Clin Oncol 2019;42:36-41.

Cite this article as: Zhao J, Zhou L, Pan Y, Chen L. A systematic review and meta-analysis of radical cystectomy in the treatment of muscular invasive bladder cancer (MIBC). Transl Androl Urol 2021;10(8):3476-3485. doi: 10.21037/tau-21-564
18. Campbell JG, Smelser WW, Lee EK. Contemporary Preoperative and Intraoperative Management of the Radical Cystectomy Patient. Urol Clin North Am 2018;45:169-81.

19. Almassi N, Cha EK, Vertosick EA, et al. Trends in Management and Outcomes among Patients with Urothelial Carcinoma Undergoing Radical Cystectomy from 1995 to 2015: The Memorial Sloan Kettering Experience. J Urol 2020;204:677-84.

20. Koga F, Kihara K. Selective bladder preservation with curative intent for muscle-invasive bladder cancer: a contemporary review. Int J Urol 2012;19:388-401.

(English Language Editor: L. Huleatt) 